\title{
Effect of Cold Deformation on Microstructures and Mechanical Properties of Austenitic Stainless Steel
}

\author{
Deming $X u^{1,2}$, Xiangliang Wan ${ }^{1,2}$, Jianxin $\mathrm{Yu}^{3}{ }^{(\mathbb{D})}$, Guang $\mathrm{Xu}{ }^{1,2}$ (D) and Guangqiang $\mathrm{Li}^{1,2, *}$ \\ 1 The State Key Laboratory of Refractories and Metallurgy, Wuhan University of Science and Technology, \\ Wuhan 430081, China; xudeming.wust@foxmail.com (D.X.); wanxiangliang@wust.edu.cn (X.W.); \\ xuguang@wust.edu.cn (G.X.) \\ 2 Key Laboratory for Ferrous Metallurgy and Resources Utilization of Ministry of Education, \\ Wuhan University of Science and Technology, Wuhan 430081, China \\ 3 Center of Analysis and Measurement, Harbin Institute of Technology, Harbin 150001, China; \\ yujianxin03242@163.com \\ * Correspondence: liguangqiang@wust.edu.cn; Tel.: +86-027-6886-2665
}

Received: 14 June 2018; Accepted: 2 July 2018; Published: 6 July 2018

\begin{abstract}
In this paper, the effect of cold deformation on the microstructures and mechanical properties of 316LN austenitic stainless steel (ASS) was investigated. The results indicated that the content of martensite increased as the cold rolling reduction also increased. Meanwhile, the density of the grain boundary in the untransformed austenite structure of CR samples increased as the cold reduction increased from $10 \%$ to $40 \%$, leading to a decreased size of the untransformed austenite structure. These two factors contribute to the improvement of strength and the decrease of ductility. High yield strengths (780-968 MPa) with reasonable elongations (30.8-27.4\%) were achieved through $20-30 \%$ cold rolling. The $10-30 \%$ cold-rolled (CR) samples with good ductility had a good strain hardening ability, exhibiting a three-stage strain hardening behavior.
\end{abstract}

Keywords: austenitic stainless steel; cold deformation; microstructures; mechanical properties

\section{Introduction}

Austenitic stainless steels (ASSs) that generally have excellent corrosion resistance, good plasticity, and a high strain hardening coefficient are widely used in food, petrochemicals, and the nuclear industry. However, their low yield strength limits their application in structural engineering and automotive industry [1,2]. The development of high strength-high ductility ASSs is considered an attractive approach to expanding their use and has been extensively studied.

There are various methods to improve the strength of ASSs, including cold deformation strengthening, bake hardening strengthening, grain size strengthening, et cetera. [3]. Due to the high strain hardening coefficient of ASSs, cold deformation strengthening with a simpler and easier process is considered an effective method and more suitable for industrial application $[4,5]$. The high yield strengths of 570-926 MPa and 554-735 MPa with reasonable elongations of $\sim 43-22 \%$ and $\sim 35-19 \%$ were achieved in 304 [6] and 316 L [7] ASSs through 10-30\% cold rolling, respectively. However, the plastic straining induced ductility loss was more pronounced than the strength increase for the ASSs as the cold rolling reduction further increased, exhibiting a typical "banana-shaped" strength-ductility trade-off [8].

The mechanical properties of cold-rolled (CR) ASSs are determined by their deformation microstructures. Normally, the austenite phase in ASSs is not a stable phase and will transform into strain-induced martensite during the plastic deformation process [9]. Martensite phase generally exhibits a higher strength and lower plasticity. According to the mix law described by Huang et al [10] 
for two phase materials, the strengths of two phase materials are determined by the volume fractions and the corresponding strengths of the two phases. The transformation from austenite phase into martensite phase will improve the strength of CR ASSs [6,11]. The phase transformation in ASSs is controlled by the stability of austenite that is determined by $\mathrm{M}_{\mathrm{d} 30}$ temperature (where $50 \%$ $\alpha$-martensite is present after $30 \%$ tensile deformation) [12]. Due to the higher content of alloy elements, some ASSs, like 316 ASSs, have a lower $\mathrm{M}_{\mathrm{d} 30}$ temperature and higher stability of austenite that inhibit the phase transformation during plastic deformation. Previous studies indicated that only $46-67 \%$ of austenite phase in 316 ASSs can be transformed into strain-induced martensite, even after $80-90 \%$ cold rolling [13-15]. Interestingly, these steels also exhibited the tendency of significant loss in plastic straining induced ductility [13-15], which cannot be explained by the mix law. Therefore, it is not enough to only consider the effect of volume fraction of the strain-induced martensite on the mechanical properties of ASSs, and the untransformed austenite evolution and its effect on mechanical properties should be considered at the same time. However, the evolution of untransformed austenite phase with increasing cold rolling reduction is less studied. The influence of untransformed austenite in CR ASSs on mechanical properties is not clear and needs in-depth studies.

In this study, the electron backscattered diffraction (EBSD) was chosen to study the evolution of untransformed austenite phase in CR 316LN ASS as the cold reduction increased from $10 \%$ to $40 \%$. Evaluating the evolution of untransformed austenite in CR ASSs by using EBSD is rarely reported and is the innovation of this paper. Furthermore, transmission electron microscopy (TEM) was used to study the evolution of the deformation microstructures as the cold rolling reduction increased. The effect of cold deformation on the mechanical properties of 316LN ASS was studied by analyzing the relationship between deformation microstructures and mechanical properties.

\section{Experimental Procedures}

The chemical composition, the stacking fault energy (SFE) based equation of Brofman and Ansell [12], and the $M_{d 30}$ temperature based on Nohara's equation [16] of 3mm-thick 316LN ASS used in this study, are shown in Table 1. The strips were cold rolled in a pilot plant with thickness reductions from $10 \%$ to $90 \%$ reduction at room temperature. The volume fraction of martensite in CR samples was determined by X-ray diffraction (XRD, Panalytical, Almelo, The Netherlands). The Vickers hardness of samples was determined by measuring more than 20 points in different regions of the samples using a microhardness tester with a $0.5 \mathrm{~kg}$ load (HV-1000B, Matsuzawa, Tokyo, Japan). The structures in original 316LN ASS and CR samples were evaluated using an OM (Axioplan2 Imaging Zeiss, Göttingen, Germany). For the CR samples, an etchant of two solutions at a 1:1 ratio was used. The first solution consists of $0.20 \mathrm{~g}$ sodium-metabisulfate in $100 \mathrm{~mL}$ distilled water and the second consists of $10 \mathrm{~mL}$ hydrochloric acid in $100 \mathrm{~mL}$ distilled water. The original samples were mechanically polished and then electrochemically etched with $60 \%$ nitric acid solution. Microstructures of $C R$ samples were examined by TEM (JEM-2100, JEOL, Tokyo, Japan). Thin foils were prepared by twin-jet electropolishing of $3 \mathrm{~mm}$ disks, punched from the specimens using a solution of $10 \%$ perchloric acid in acetic acid as the electrolyte. EBSD was utilized to evaluate the microstructures and grain boundary of $0-40 \% \mathrm{CR}$ samples. For that purpose, the samples were electrochemically etched with $20 \%$ perchloric acid alcohol solution operated at $25^{\circ} \mathrm{C}$ with an applied potential of $15 \mathrm{~V}$. The size of the austenite structure in EBSD micrographs was determined by analyzing grain boundary misorientation over $2^{\circ}$. The original and CR strips were machined to make tensile samples with a profile of $140 \times 20 \mathrm{~mm}$ and a gage length of $65 \mathrm{~mm}$. The uniaxial tensile tests were carried out at room temperature at an engineering strain rate of $5 \times 10^{-4} \mathrm{~s}^{-1}$ and each specimen was tested three times to obtain an average value for each mechanical property. 
Table 1. Chemical compositions, stacking fault energy (SFE), and $\mathrm{M}_{\mathrm{d} 30}$ of the investigated steel (wt, \%).

\begin{tabular}{ccccccccc}
\hline $\mathbf{C}$ & $\mathbf{S i}$ & $\mathbf{M n}$ & $\mathbf{N}$ & $\mathbf{C r}$ & $\mathbf{N i}$ & $\mathbf{M o}$ & $\mathbf{S F E}, \mathbf{m J} / \mathbf{m}^{2}$ & $\mathbf{M}_{\mathrm{d} 30},{ }^{\circ} \mathbf{C}$ \\
\hline 0.04 & 0.34 & 1.15 & 0.048 & 18.06 & 8.33 & 0.051 & 18.9 & 6.2 \\
\hline
\end{tabular}

\section{Results}

\subsection{The Microstructural Evolution with Increasing Cold Rolling Reduction}

Optical micrographs of 316LN commercial ASS and 10\%, 30\%, 50\%, 70\%, and 90\% CR samples are presented in Figure 1. As shown in Figure 1a, the coarse-grained austenite existed in this commercial steel. The content of strain-induced martensite increased as the cold rolling reduction increased, as shown in Figure 1b-f. Many shear bands were discovered in the austenite phase of the $10 \% \mathrm{CR}$ sample (Figure $1 \mathrm{~b}$ ). When the cold reduction increased to $30 \%$, some strain-induced martensite formed at shear bands. When the cold reduction increased to $50 \%$, the untransformed austenite was elongated along the rolling direction (Figure 1d). The content of martensite further increased and the formed martensite segmented the untransformed austenite when the cold reduction was increased to $70 \%$, as shown in Figure 1e. When the cold reduction increased to $90 \%$, the large block of untransformed austenite still existed. Meanwhile, the formed martensite seemed to be divided into fine martensite and mixed with fine austenite structure (white circle in Figure 1f). The shear bands were basically replaced by martensite and became difficult to distinguish, as shown in Figure $1 \mathrm{f}$.
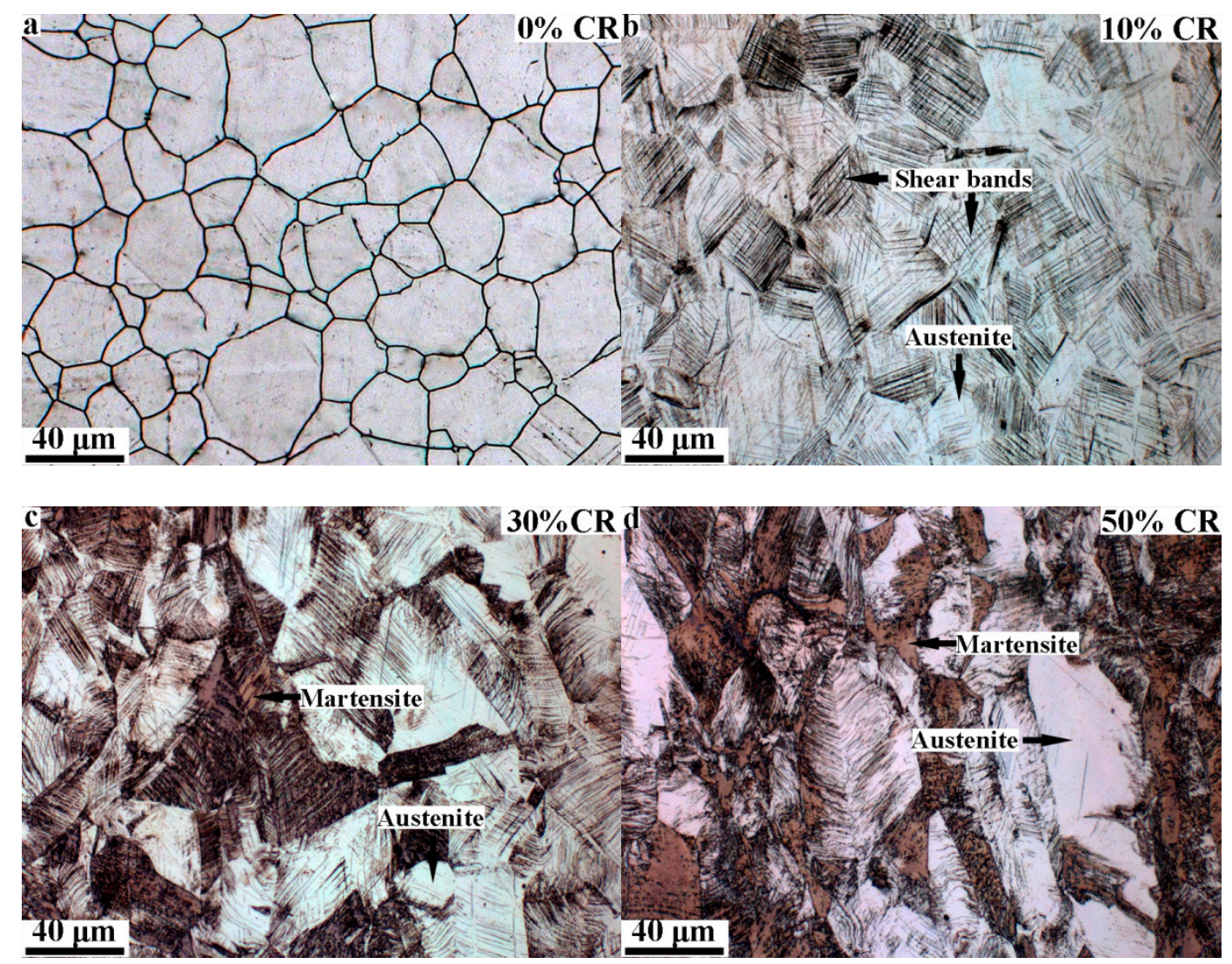

Figure 1. Cont. 


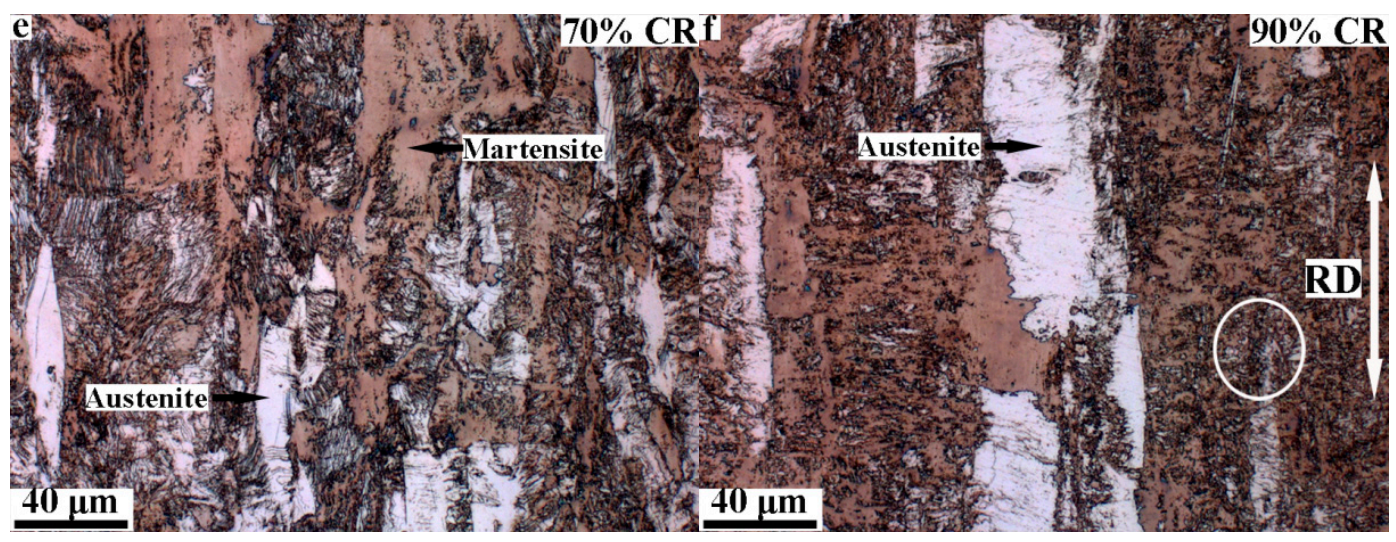

Figure 1. Optical micrographs of microstructures for (a) original; (b) $10 \%$ CR; (c) $30 \%$ CR; (d) $50 \%$ CR; (e) 70\% CR; and (f) 90\% CR 316LN ASSs. The cold rolling direction (RD) is shown in (f). The straw color phase is the strain-induced martensite and the white phase is the austenite matrix.

The XRD patterns of 316LN commercial ASS, $10 \%, 30 \%, 50 \%, 70 \%$, and $90 \%$ CR samples are presented in Figure 2a. According to the XRD patterns, only $\alpha$-martensite formed during cold deformation and the increased cold reduction led to the development of $\alpha$-martensite peaks. The measurement of volume fractions of $\dot{\alpha}$-martensite in CR ASSs based on XRD has been reported in many studies [17-19]. The measured results based on the equation of Dickson [17] are presented in Figure $2 \mathrm{~b}$. It can be observed that the volume fraction of $\alpha$-martensite increased with increasing cold reduction and about $46 \%$ $\alpha$-martensite was achieved in the $90 \%$ CR sample.
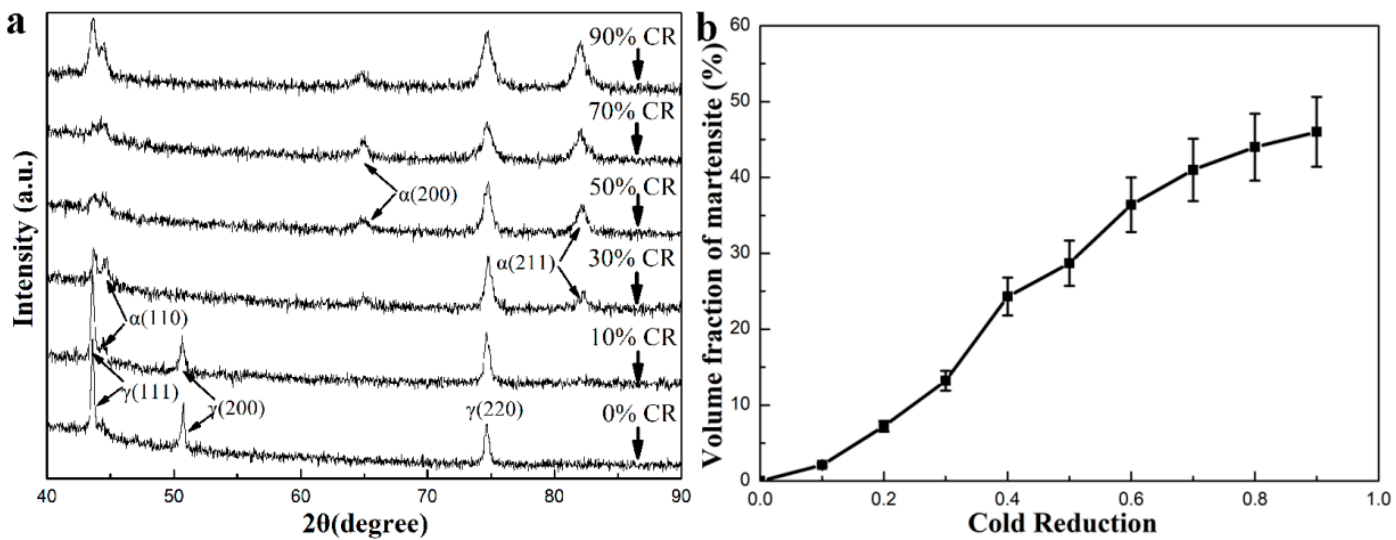

Figure 2. (a) X-ray diffraction patterns of $316 \mathrm{LN} \mathrm{ASS,} 10 \%, 30 \%, 50 \%, 70 \%$, and $90 \%$ CR samples and (b) the volume fractions of $\alpha$-martensite in CR samples as a function of cold reduction.

Figure 3 illustrates that the microstructures evolve with the increasing cold rolling reduction. As shown in Figure 3a,b, shear bands and mechanical twins existed in the $10 \%$ CR sample and the dislocations gathered at shear bands and twins' boundaries. When the cold reduction increased to $30 \%$, the strain-induced martensite was observed and the dislocation movement was suppressed by the martensite boundary, which resulted in the gathering of dislocations around the martensite boundary (Figure 3c). Meanwhile, dislocation boundaries (DB) were formed to segment the untransformed austenite structure (Figure 3d). When the cold reduction increased to $50 \%$, many martensite laths formed (Figure 3e). Furthermore, the dislocation-cell-type martensite was observed in samples when the cold reduction was increased to $90 \%$ (Figure 3f). 

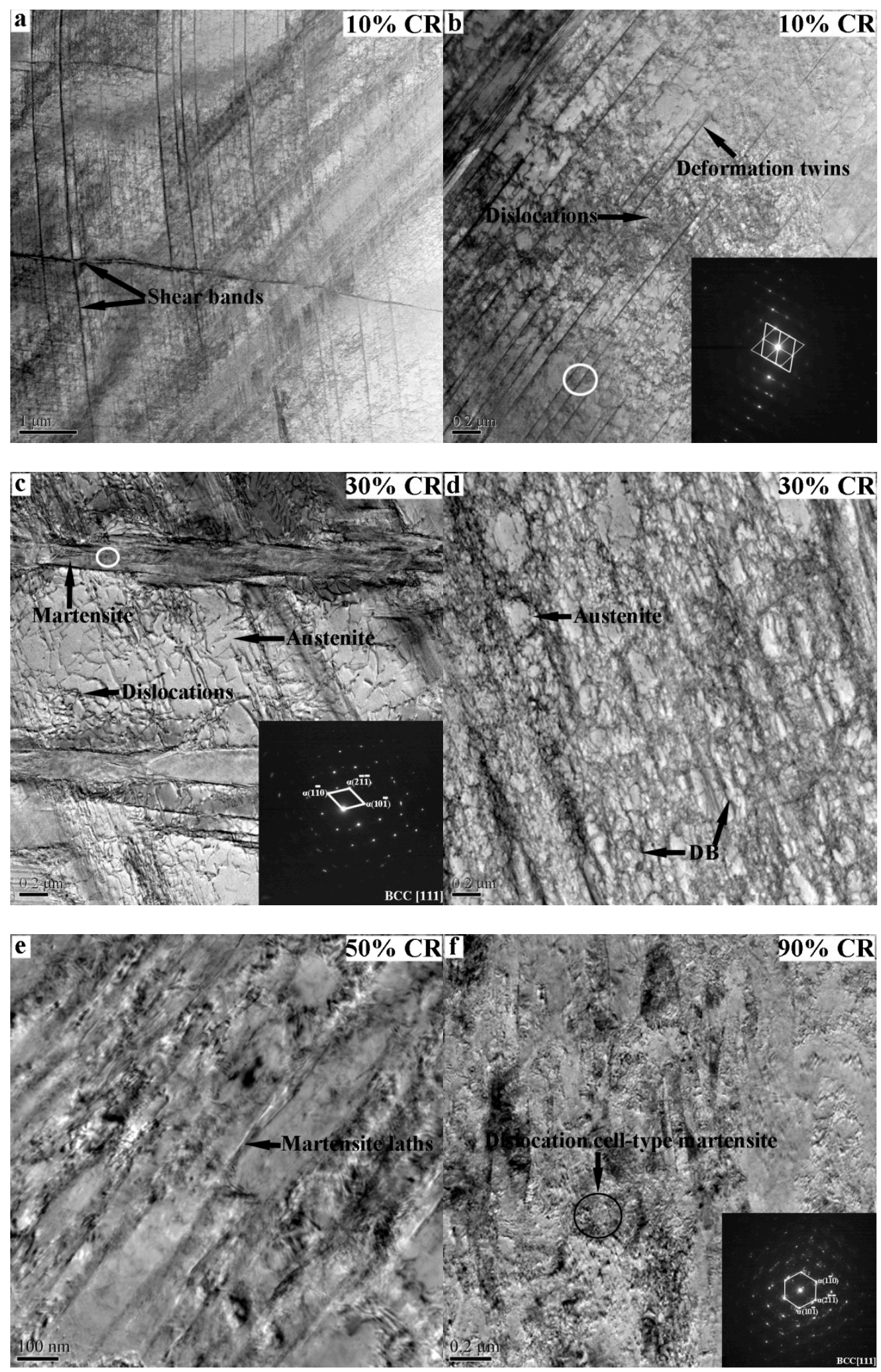

Figure 3. Representative bright field transmission electron micrographs of deformation microstructures in (a,b) 10\% CR; (c,d) 30\% CR; (e) 50\% CR; and (f) $90 \%$ CR samples. The diffraction pattern confirmed (b) deformation twin, (c) martensite lath, and (f) dislocation-cell-type martensite. DB in (b) means dislocations boundary. 
The original and 10-40\% CR samples were characterized by EBSD and are presented in Figure 4. The main structure of the original sample was coarse austenite grains with many annealing twins (Figure 4a). A small amount of strain-induced martensite and grain boundaries formed in austenite grains after $10 \%$ cold rolling. The formed grain boundary was mainly a low angle grain boundary $\left(0^{\circ}<\mathrm{LAGB}<15^{\circ}\right)$. The density of the grain boundary and volume fraction of martensite increased with the increasing cold rolling reduction. Figure $4 \mathrm{f}$ indicates that the densities of both LAGB and the high angle grain boundary $\left(\mathrm{HAGB}>15^{\circ}\right.$ ) increased with the increasing cold rolling reduction. The difference between LAGB and HAGB is that the density of LAGB first increased rapidly and then increased slowly when the cold reduction increased from 10\% to 40\%, while for HAGB, the increase rate change is the opposite. Sizes of austenite structure, percentage fractions, and densities of the austenite grain boundary with the different misorientation ranges based on Figure 4 are listed in Table 2 . As shown in Table 2, the sizes of the austenite structure decreased with the increasing cold reduction. Figure 5a-d show the IPF map and Figure 5e-h show the corresponding misorientation variation along the black lines in untransformed austenite grains of $10 \%$ CR, 20\% CR, 30\% CR, and 40\% CR samples, respectively. The results indicate that the main misorientation of point to point in untransformed austenite grains of the $10 \%$ CR sample was below $15^{\circ}$. When the cold reduction increased to $30 \%$ and $40 \%$, the densities of high misorientation $\left(>15^{\circ}\right)$ increased obviously. The average numbers of misorientation in untransformed austenite grains of CR samples increased rapidly as the cold reduction increased from $10 \%$ to $40 \%$, as shown in Figure 5e-h.

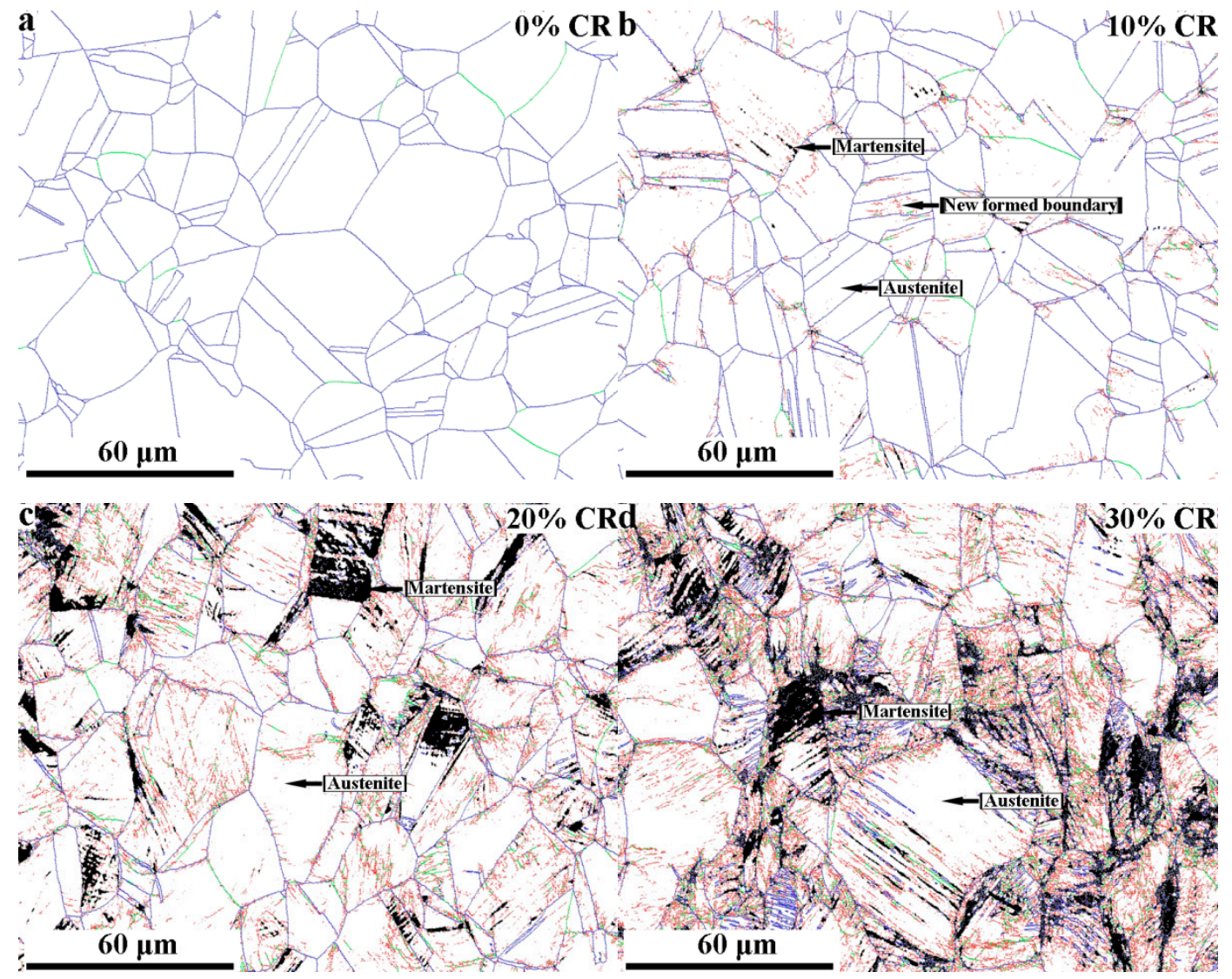

Figure 4. Cont. 

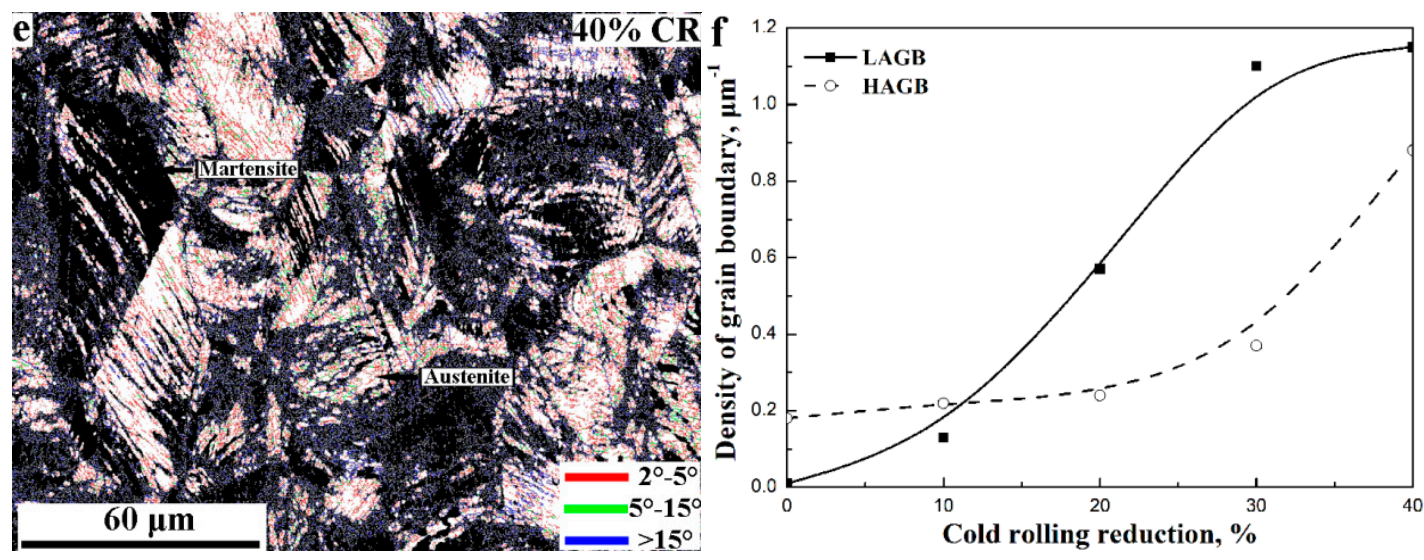

Figure 4. Electron backscattered diffraction (EBSD) micrographs grain boundary reconstruction maps for austenite phase of (a) original; (b) 10\% CR; (c) 20\% CR; (d) 30\% CR; and (e) $40 \%$ CR samples, respectively; (f) The variation density of low angle grain boundary (LAGB) and high angle grain boundary (HAGB) as a function of cold rolling reduction. The white area is the austenite structure and the black area is martensite.
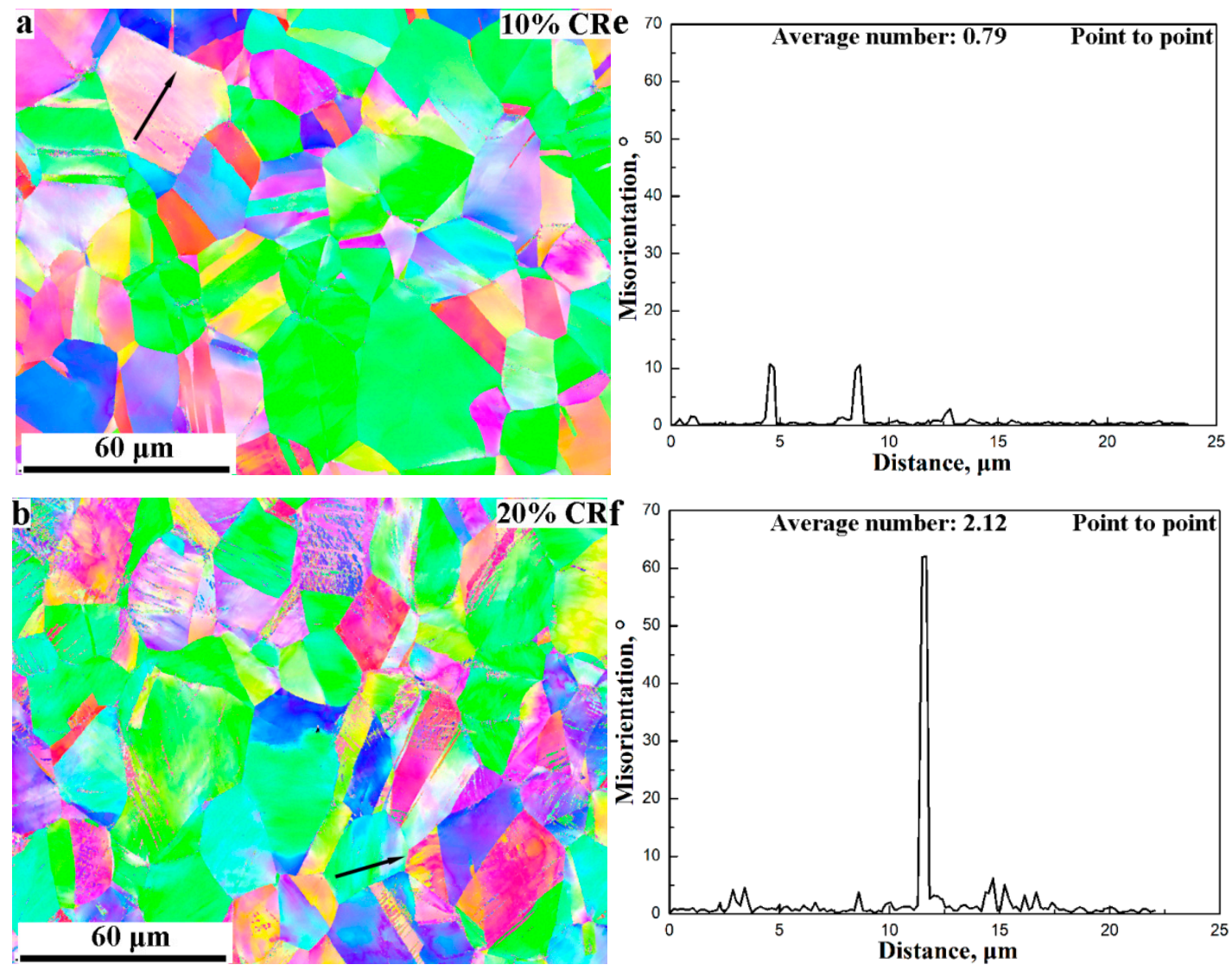

Figure 5. Cont. 

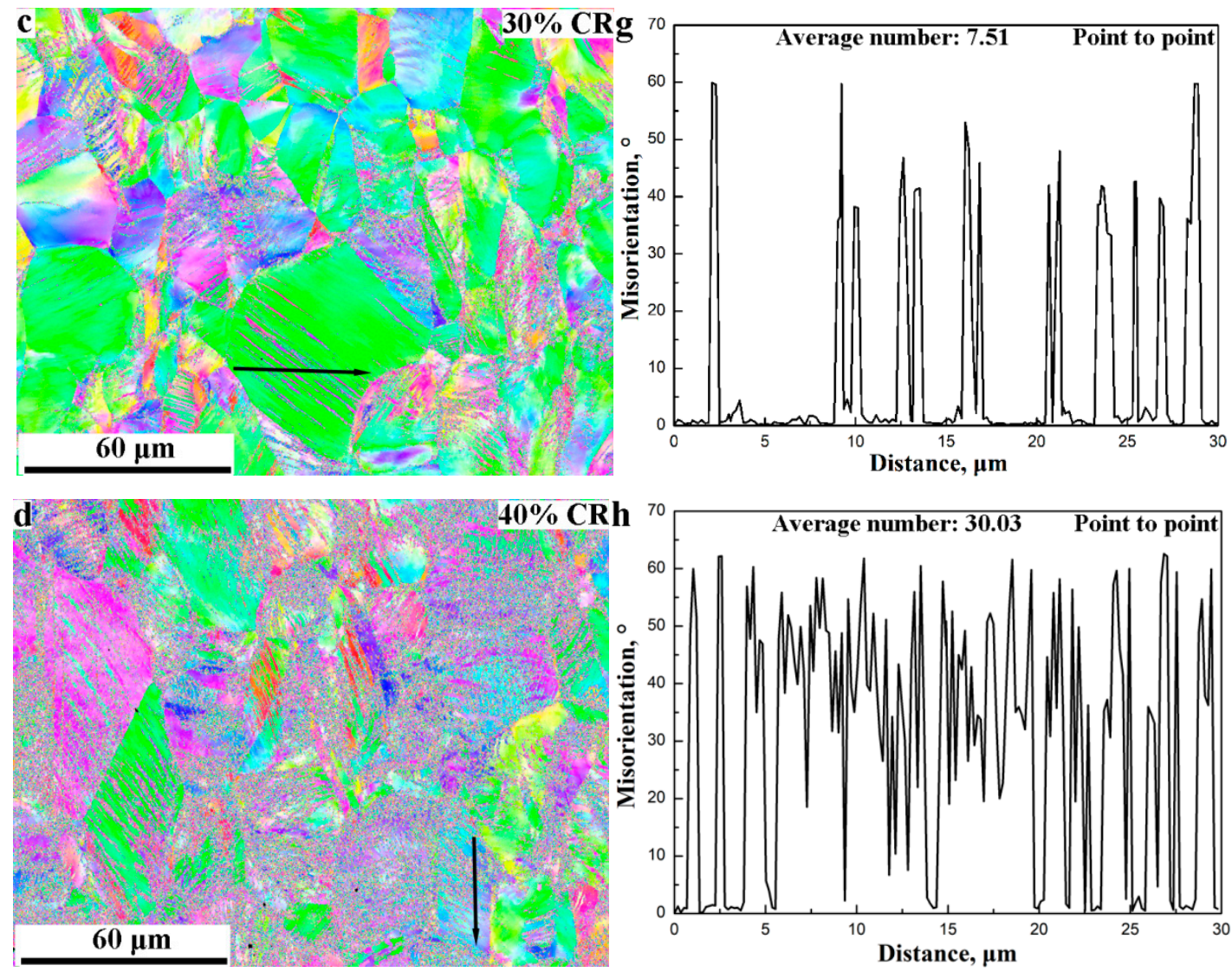

Figure 5. (a-d) IPF images for (a) 10\% CR; (b) 20\% CR; (c) 30\% CR; and (d) 40\% CR samples, respectively. (e-h) Misorientation variations along the black lines (black lines in figures) in untransformed austenite grain for (e) 10\% CR; (f) $20 \%$ CR; (g) 30\% CR; and (h) 40\% CR samples, respectively.

Table 2. Austenite structure sizes, percentage fractions, and densities of the austenitic grain boundary with different misorientation ranges of samples with varying cold reductions.

\begin{tabular}{|c|c|c|c|c|c|}
\hline \multirow{2}{*}{$\begin{array}{l}\text { Cold Rolling } \\
\text { Reduction, \% }\end{array}$} & \multirow{2}{*}{ Structure Size, $\mu \mathrm{m}$} & \multicolumn{2}{|c|}{ Percentage Fraction, $\%$} & \multicolumn{2}{|c|}{ Density, Length/Area, $\mu \mathrm{m}^{-1}$} \\
\hline & & $2-15^{\circ}$ & $15-65^{\circ}$ & $2-15^{\circ}$ & $15-65^{\circ}$ \\
\hline 0 & 9.0 & 5.2 & 94.8 & 0.01 & 0.18 \\
\hline 10 & 7.3 & 35.9 & 64.1 & 0.13 & 0.22 \\
\hline 20 & 2.8 & 73.1 & 26.9 & 0.57 & 0.24 \\
\hline 30 & 1.3 & 72.8 & 27.2 & 1.1 & 0.37 \\
\hline 40 & 0.87 & 56.7 & 43.3 & 1.15 & 0.88 \\
\hline
\end{tabular}

\subsection{The Mechanical Properties of CR Samples}

The engineering stress-engineering strain $\left(\sigma_{\mathrm{E}} \varepsilon_{\mathrm{E}}\right)$ curves of $10 \%, 30 \%, 50 \%, 70 \%$, and $90 \% \mathrm{CR}$ samples are shown together with those of the original sample in Figure 6a. The mechanical properties that changed due to the cold rolling reduction are listed in Table 3. It was found that the original sample exhibited a low average yield strength of $281 \mathrm{MPa}$ and high average elongation of $52 \%$. After $30 \%$ cold rolling, its average yield strength increased to $968 \mathrm{MPa}$ with an average elongation of $27.4 \%$. When the cold reduction increased to $90 \%$, the yield strength rose to $1870 \mathrm{MPa}$, nearly seven times that of the original sample, but the elongation decreased to $1.3 \%$. Figure $6 \mathrm{~b}$ shows that the average tensile/yield strength increased, but the average elongation decreased, when the cold rolling reduction increased. The average Vickers hardness increased as the cold rolling reduction increased. 
When the cold reduction increased to $90 \%$, the hardness value increased to 549.4 , which is about three times that of the original sample.
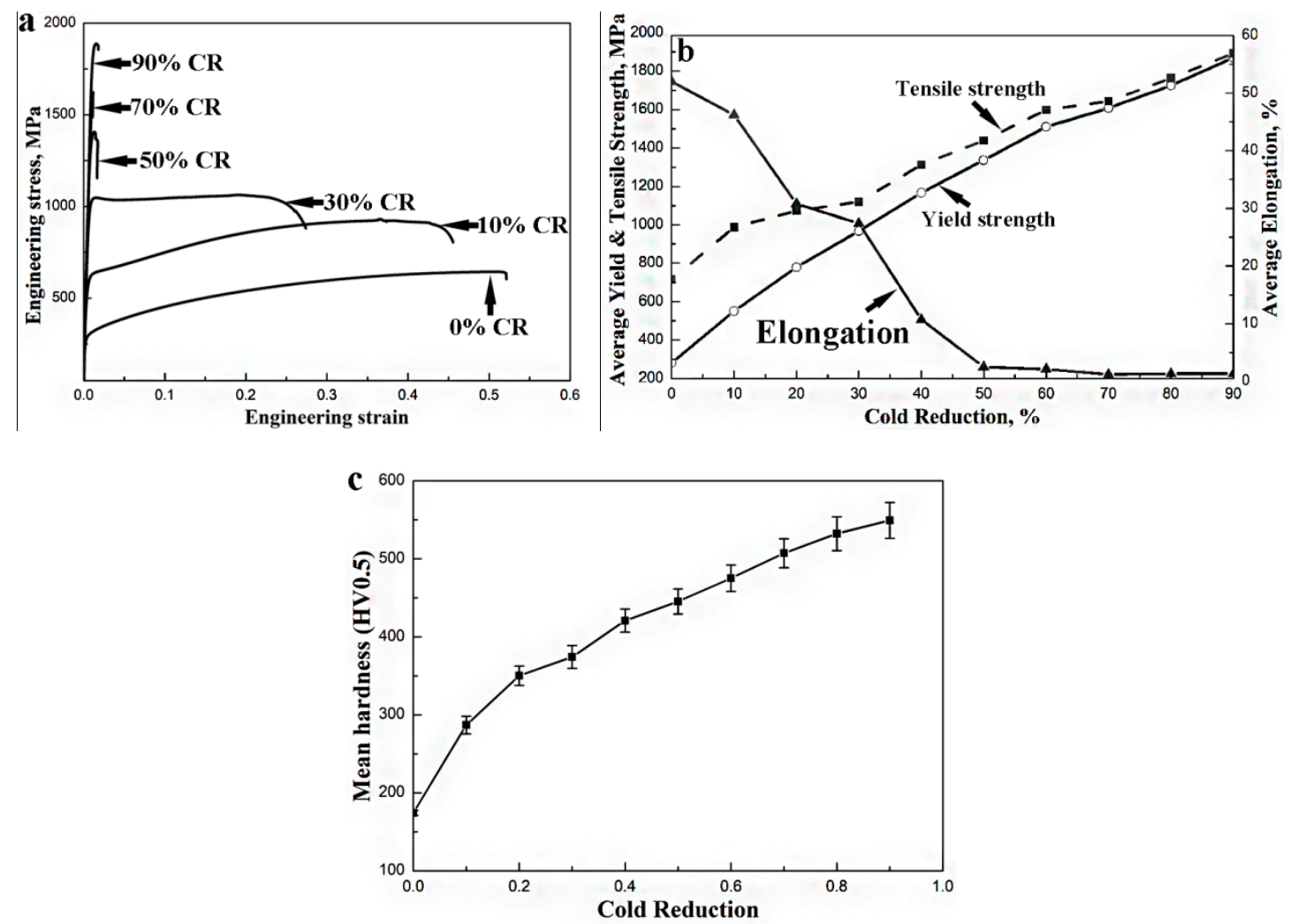

Figure 6. (a) Engineering stress-engineering strain behavior for original, 10\%, 30\%, 50\%, 70\%, and 90\% CR samples; (b) variation average yield/tensile strengths and elongations; and (c) Vickers hardness as a function of cold rolling reduction.

Table 3. Variation of martensite volume fractions, Vickers harnesses, mean tensile and yield strengths, and mean elongations with \% cold rolling reduction for 316LN ASS.

\begin{tabular}{cccccc}
\hline $\begin{array}{c}\text { Cold Rolling } \\
\text { Reduction, } \%\end{array}$ & $\begin{array}{c}\text { Martensite Volume } \\
\text { Fraction, } \mathbf{\%}\end{array}$ & $\begin{array}{c}\text { Vickers Hardness, } \\
\text { HV0.5 }\end{array}$ & $\begin{array}{c}\text { Mean Tensile } \\
\text { Strength, MPa }\end{array}$ & $\begin{array}{c}\text { Mean Yield } \\
\text { Strength, MPa }\end{array}$ & Mean Elongation, \% \\
\hline 0 & 0 & 174.2 & 644 & 281 & 52.0 \\
10 & 2.1 & 287.0 & 931 & 551 & 780 \\
20 & 7.2 & 360.2 & 1021 & 968 & 27.4 \\
30 & 13.2 & 374.2 & 1071 & 1167 & 1337 \\
40 & 24.3 & 420.8 & 1274 & 1510 & 2.5 \\
50 & 28.7 & 445.4 & 1407 & 1608 & 1.7 \\
60 & 36.4 & 475.3 & 1576 & 1725 & 1.3 \\
70 & 41.1 & 507.2 & 1750 & 1870 \\
\hline
\end{tabular}

\subsection{Strain Hardening Behaviors of CR Samples}

The 10\% CR and 30\% CR samples with good ductility were selected to study the strain hardening behaviors and their strain hardening rates (SHRs; $\mathrm{d} \sigma_{\mathrm{T}} / \mathrm{d} \varepsilon_{\mathrm{T}}$ ) were plotted as a function of true strain, presented in Figure 7. The SHR plots of selected samples can be divided into three stages, as shown in Table 4. The SHRs first decreased (Stage A), then increased (Stage B), before finally decreasing again (Stage C) with increasing true strain. 


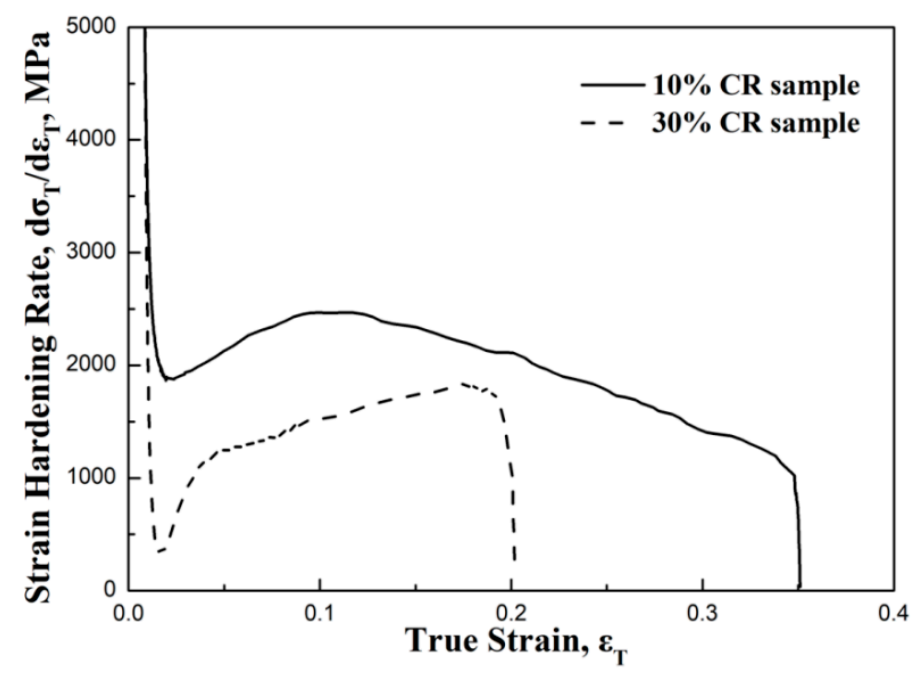

Figure 7. Strain hardening rate for $10 \% \mathrm{CR}(\mathrm{A} 1, \mathrm{~B} 1, \mathrm{C} 1)$ and $30 \% \mathrm{CR}$ samples $(\mathrm{A} 2, \mathrm{~B} 2, \mathrm{C} 2)$.

Table 4. Values of plastic strain of the samples at each stage. The data are taken from Figure 7.

\begin{tabular}{cccc}
\hline Sample & Stage A & Stage B & Stage C \\
\hline $10 \% \mathrm{CR}$ & $\varepsilon_{\mathrm{T}}<0.02$ & $0.023<\varepsilon_{\mathrm{T}}<0.09$ & $0.09<\varepsilon_{\mathrm{T}}<0.35$ \\
$30 \% \mathrm{CR}$ & $\varepsilon_{\mathrm{T}}<0.017$ & $0.017<\varepsilon_{\mathrm{T}}<0.18$ & $0.18<\varepsilon_{\mathrm{T}}<0.2$ \\
\hline
\end{tabular}

\section{Discussion}

In this paper, the effect of cold deformation on the mechanical properties of 316LN ASS was studied. It is well-known that the microstructural characteristics are a major factor determining the mechanical properties of steels. Therefore, the effect of cold deformation on microstructural evolution and the relationship between the microstructures and mechanical properties of CR 316LN ASS were discussed. The ductility of the ASSs is related to their strain hardening behavior. To obtain high strength 316LN ASS with a reasonable ductility, the strain hardening behaviors of CR samples were discussed.

\subsection{The Effect of Cold Deformation on the Microstructures}

The deformation microstructures formed in ASSs during the plastic deformation process depend on their deformation mechanisms, which are determined by their SFEs. The SFE of the 316LN ASS at room temperature is $\sim 18.9 \mathrm{~mJ} / \mathrm{m}^{2}$ (Table 1 ) and both the strain induced martensite and the mechanical twin could form during plastic deformation $[13,20]$. When the cold rolling reduction increased, the shear bands comprised of slip bands and mechanical twins formed in austenite grains and then the strain-induced martensite nucleated at the intersection of shear bands [21-23]. The formed $\dot{\alpha}$-martensite replaced the shear bands and the shear bands gradually disappeared as the cold rolling reduction increased. Furthermore, the martensite lath could be broken and mixed with untransformed austenite to form dislocation-cell-type martensite that has a higher density of dislocation (Figure 3f) [24].

Previous studies $[25,26]$ have indicated that heavily cold worked metals could be subdivided by grain boundaries and dislocation boundaries. The cold work inducing the formation of the grain boundary was also found in CR AZ91 alloy [27] and 308L stainless steel [28]. In this 316LN ASS, in addition to dislocation grain boundaries, the boundaries of mechanical twins and strain-induced martensite formed during the $\mathrm{CR}$ process can also subdivide untransformed austenite, leading to the decrease of the untransformed austenite structure size. The EBSD results in Figure 4 revealed a similar tendency, where the increased density of grain boundaries led to a decreasing untransformed austenite structure size. Hughes and Hansen's study [29] indicated that the continued subdivision of 
grains into crystallites surrounded by dislocation boundaries leads to a large orientation spread based on dislocation accumulation processes. The main grain boundaries formed in the $10 \%$ CR sample were LAGB that may originate from the dislocation boundary formed by dislocation accumulated at twins' boundaries or shear bands. The rapidly increasing density of LAGB as the cold reduction increased from $10 \%$ to $30 \%$ could be attributed to the increased dislocation boundaries caused by the increasing density of dislocation. The difficult dislocation boundaries formed could show an operation of different slip system combinations within the individual crystallites, leading to the possibility of different parts of a grain rotating towards different stable end orientations [29]. If such end orientations are not far apart, large misorientations within the original grain can build up. Considering that the density of the dislocation boundary in the untransformed austenite grains increases with the increasing cold rolling reduction, the probability of large misorientations within the original grains increases with the increasing cold rolling reduction, leading to the increasing density of HAGB. The results in Figures 4 and 5 illustrate this viewpoint very well as the variations of HAGB densities are in good agreement with the variations of the average numbers of misorientations in the original austenite grains.

\subsection{Effect of Microstructures on Mechanical Properties}

The previous section has shown that cold deformation could promote strain-induced martensite formation. Compared with the austenite with a face centered cubic (fcc) crystal structure, the $\alpha$-martensite with a body-centered cubic (bcc) crystal structure has fewer slip directions and a larger lattice resistance, which means that $\alpha$-martensite is more difficult to slip in the process of plastic deformation [30]. The strain-induced martensite formed during cold deformation could effectively improve the strength of the samples. Furthermore, although there are large blocks of untransformed austenite existing in CR samples, the results of TEM and EBSD have indicated that a high density grain boundary existed in these austenite structures. The grain boundary can hinder the movement of dislocations, which could reduce the stress concentration and improve the strength of the samples. Meanwhile, the increasing volume fraction of martensite and dislocation density as the cold rolling reduction increased resulted in the increasing Vickers hardness [31].

However, the high density dislocation in martensite and its uneasy sliding contribute to its poor plasticity. The high density of the grain boundary in the untransformed austenite structure will significantly hinder the movement of dislocations. Furthermore, austenite structure refinement could enhance the stability of austenite, which inhibits the martensite transformation during the plastic deformation, resulting in a decrease in the ductility [32].

\subsection{Effect of CR Microstructures on Strain Hardening Behavior}

The 10\% CR and 30\% CR samples presenting three-stage strain hardening curves and high SHRs reflect the high strain hardening ability. However, there are subtle differences between the samples in the SHRs, which are caused by their different microstructures. The strain range at stage A in $10 \%$ CR samples is larger than that in 30\% CR samples. The variation of SHRs at an early stage is usually affected by the nucleation and slip of dislocation in ASSs [33-35]. Compared with the 10\% CR sample, the 30\% CR sample has more dislocations and a higher density grain boundary, which are not conducive to dislocation movement during the tensile process, resulting in its smaller strain range at stage $\mathrm{A}$. The strain range at stages $\mathrm{B}$ and $\mathrm{C}$ was considered beneficial to plasticity in ASSs that was attributed to the transformation induced plasticity (TRIP) or twinning induced plasticity (TWIP) effect [36]. The tensile induced martensite or mechanical twin will nucleate and grow at stages $\mathrm{B}$ and C [37]. When the cold reduction increased from $10 \%$ to $30 \%$, the austenite structure size decreased from $7.3 \mu \mathrm{m}$ to $1.3 \mu \mathrm{m}$ (Table 2). Grain refinement can increase the stability of austenite and inhibit the tensile induced martensite formation during plastic deformation [38], making the strain range at stages B and C in the 30\% CR sample smaller than that of the $10 \%$ CR sample. With the increase of cold reduction, the finer austenite structure in samples is not conducive to the nucleation and movement 
of dislocation. Furthermore, the high content of martensite in the samples reduces the capacity to accommodate dislocations. These factors lead to the rapid decrease of the strain hardening ability of the samples when the cold rolling reduction increased.

\section{Conclusions}

The effects of cold rolling reduction on the microstructures and mechanical properties of 316LN ASS were studied. The conclusions can be summarized as follows:

(1) The yield strength of commercial 316LN ASS increased from $281 \mathrm{MPa}$ to 780-968 MPa and it maintained a reasonable elongation value of $30.8-27.4 \%$ through thickness reduction of $20-30 \%$ cold rolling.

(2) The size of untransformed austenite in CR samples decreased when cold reduction increased from $10 \%$ to $40 \%$. The decreased size of untransformed austenite was attributed to the increasing boundary density of dislocations, mechanical twins, and strain-induced martensite that formed during the $\mathrm{CR}$ process.

(3) The grain refinement of untransformed austenite phase and increasing content of strain-induced martensite resulted in an increased yield/tensile strength and decreased ductility of 316LN ASS under the influence of increasing the cold rolling reduction.

(4) The CR 316LN ASSs with high yield strengths and reasonable elongations had a good strain hardening ability and exhibited a three-stage strain hardening behavior.

In this paper, the increased yield/tensile strength and decreased elongation of CR 316LN ASS are attributed to grain refinement of the untransformed austenite phase and increasing content of strain-induced martensite. However, which of these two factors plays a major role is not clear. We plan to obtain a fully deformation austenite structure and fully strain-induced martensite through controlling rolling temperature and reduction in the next work. The effect of a fully deformation austenite structure or fully strain-induced martensite on the mechanical properties of ASSs will be studied in the next work.

Author Contributions: X.W. and G.L., supervisor, conceived and designed the experiments; D.X., doctoral student, conducted experiments, analyzed the data and wrote the paper; J.Y., conducted experiments; G.X., conducted experiments.

Funding: This research was funded by National Natural Science Foundation of China (No. 51501134).

Conflicts of Interest: The authors declare no conflict of interest.

\section{References}

1. European Steel Technology Platform (ESTEP). Strategic Research Agenda. A Vision for the Future of the Steel Sector; European Commission: Brussels, Belgium, 2005.

2. Andersson, R.; Schedin, E.; Magnusson, C.; Ocklund, J.; Persson, A. Stainless steel components in automotive vehicles. In Proceedings of the 4th European Stainless Steel Science and Market Congress, Paris, France, 10-13 June 2002; p. 57.

3. Karjalainen, L.P.; Taulavuori, T.; Sellman, M.; Kyröläinen, A. Some Strengthening Methods for Austenitic Stainless Steels. Steel Res. Int. 2008, 79, 404-412. [CrossRef]

4. Maki, T. Stainless steel: Progress in thermomechanical treatment. Curr. Opin. Solid State Mater. Sci. 1997, 2 , 290-295. [CrossRef]

5. Padilha, A.F.; Plaut, R.L.; Rios, P.R. Annealing of cold-worked austenitic stainless steels. Iron Steel Inst. Jpn. 2003, 43, 135-143. [CrossRef]

6. Milad, M.; Zreiba, N.; Elhalouani, F.; Baradai, C. The effect of cold work on structure and properties of AISI 304 stainless steel. J. Mater. Process. Technol. 2008, 203, 80-85. [CrossRef]

7. Hou, X.; Zheng, W.; Song, Z.; Long, J. Effect of cold working on mechanical behavior and microstructure of 316L stainless steel. J. Iron Steel Res. 2013, 25, 53-57. (In Chinese) 
8. Raabe, D.; Ponge, D.; Dmitrieva, O.; Sander, B. Nanoprecipitate-hardened 1.5 GPa steels with unexpected high ductility. Scr. Mater. 2009, 60, 1141-1144. [CrossRef]

9. Padilha, A.F.; Rios, P.R. Decomposition of austenite in austeniticstainless steels. Iron Steel Inst. Jpn. 2002, 42, 325-337. [CrossRef]

10. Huang, G.L.; Matlock, D.; Krauss, G. Martensite formation, strain rate sensitivity, and deformation behavior of type 304 stainless steel sheet. Metall. Trans. A 1989, 20, 1239-1246. [CrossRef]

11. Hedayati, A.; Najafizadeh, A.; Kermanpur, A.; Forouzan, F. The effect of cold rolling regime on microstructure and mechanical properties of AISI 304L stainless steel. J. Mater. Process. Technol. 2010, 210, 1017-1022. [CrossRef]

12. Brofman, P.J.; Ansell, G.S. On the effect of carbon on the stacking fault energy of austenitic stainless steels. Metall. Trans. A 1978, 9, 879-880. [CrossRef]

13. Xu, D.M.; Li, G.Q.; Wan, X.L.; Xiong, R.L.; Xu, G.; Wu, K.M.; Somani, M.C.; Misra, R.D.K. Deformation behavior of high yield strength-high ductility ultrafine-grained $316 \mathrm{LN}$ austenitic stainless steel. Mater. Sci. Eng. A 2017, 688, 407-415. [CrossRef]

14. Wu, H.; Niu, G.; Cao, J.; Yang, M. Annealing of strain-induced martensite to obtain micro/nanometre grains in austenitic stainless. Mater. Sci. Technol. 2017, 33, 480-486. [CrossRef]

15. Eskandari, M.; Najafizadeh, A.; Kermanpur, A. Effect of strain-induced martensite on the formation of nanocrystalline 316L stainless steel after cold rolling and annealing. Mater. Sci. Eng. A 2009, 519, 46-50. [CrossRef]

16. Nohara, K.; Ono, Y.; Ohashi, N. Composition and grain size dependencies of strain-induced martensitic transformation in metastable austenitic stainless steels. Iron Steel Inst. Jpn. 1977, 63, 772-782. [CrossRef]

17. Dickson, M.J. The significance of texture parameters in phase analysis by X-ray diffraction. J. Appl. Crystallogr. 1969, 2, 176-180. [CrossRef]

18. Johannsen, D.L.; Kyrolainen, A.; Ferreira, P.J. Influence of annealing treatment on the formation of nano/submicron grain size AISI 301 Austenitic stainless steels. Metall. Mater. Trans. A 2006, 37, 2325-2338. [CrossRef]

19. Egea, A.J.S.; Rojas, H.A.G.; Celentano, D.J.; Peiró, J.J. Mechanical and metallurgical changes on 308L wires drawn by electropulses. Mater. Des. 2016, 90, 1159-1169. [CrossRef]

20. Lee, T.H.; Shin, E.; Oh, C.S.; Ha, H.Y.; Kim, S.J. Correlation between stacking fault energy and deformation microstructure in high-interstitial-alloyed austenitic steels. Acta Mater. 2010, 58, 3173-3186. [CrossRef]

21. Murr, L.E.; Staudhammer, K.P.; Hecker, S.S. Effects of strain state and strain rate on deformation-induced transformation in 304 stainless steel: Part II. Microstructural study. Metall. Trans. A 1982, 13, 627-635. [CrossRef]

22. Choi, J.Y.; Jin, W. Strain induced martensite formation and its effect on strain hardening behavior in the cold drawn 304 austenitic stainless steels. Scr. Mater. 1997, 36, 99-104. [CrossRef]

23. Meyers, M.A.; Xu, Y.B.; Xue, Q.; Pérez-Prado, M.T.; McNelley, T.R. Microstructural evolution in adiabatic shear localization in stainless steel. Acta Mater. 2003, 51, 1307-1325. [CrossRef]

24. Misra, R.D.K.; Nayak, S.; Mali, S.A.; Shah, J.S.; Somani, M.C.; Karjalainen, L.P. On the Significance of Nature of Strain-Induced Martensite on Phase-Reversion-Induced Nanograined/Ultrafine-Grained Austenitic Stainless Steel. Metall. Trans. A 2010, 41, 3. [CrossRef]

25. Bellier, S.P.; Doherty, R.D. The structure of deformed aluminium and its recrystallization-investigations with transmission Kossel diffraction. Acta Metall. 1977, 25, 521-538. [CrossRef]

26. Hughes, D.A.; Hansen, N. High angle boundaries and orientation distributions at large strains. Scr. Mater. 1995, 33, 315-321. [CrossRef]

27. Sheng, Y.; Hua, Y.; Wang, X.; Zhao, X.; Chen, L.; Zhou, H.; Wang, J.; Berndt, C.C.; Li, W. Application of high-density electropulsing to improve the performance of metallic materials: Mechanisms, microstructure and properties. Materials 2018, 11, 185. [CrossRef] [PubMed]

28. Egea, A.J.S.; González-Rojas, H.A.; Celentano, D.J.; Perió, J.J.; Cao, J. Thermomechanical analysis of an electrically assisted wire drawing process. J. Manuf. Sci. Eng. 2017, 139, 111017. [CrossRef]

29. Hughes, D.A.; Hansen, N. High angle boundaries formed by grain subdivision mechanisms. Acta Mater. 1997, 45, 3871-3886. [CrossRef]

30. Cui, Z.Q.; Liu, B.X. Principles of Metallography and Heat Treatment; Harbin Institute of Technology Press: Harbin, China, 2004. (In Chinese) 
31. Zhang, N.; Wang, Y. Dislocations and hardness of hard coatings. Thin Solid Films 1992, 214, 4-5. [CrossRef]

32. Yan, F.K.; Liu, G.Z.; Tao, N.R.; Lu, K. Strength and ductility of 316L austenitic stainless steel strengthened by nano-scale twin bundles. Acta Mater. 2012, 60, 1059-1071. [CrossRef]

33. Ding, H.; Ding, H.; Song, D.; Tang, Z.; Yang, P. Strain hardening behavior of a TRIP/TWIP steel with 18.8\% Mn. Mater. Sci. Eng. A 2011, 528, 868-873. [CrossRef]

34. Challa, V.S.A.; Wan, X.L.; Somani, M.C.; Karjalainen, L.P.; Misra, R.D.K. Significance of interplay between austenite stability and deformation mechanisms in governing three-stage work hardening behavior of phase-reversion induced nanograined/ultrafine-grained (NG/UFG) stainless steels with high strength-high ductility combination. Scr. Mater. 2014, 86, 60-63.

35. Matsuoka, Y.; Iwasaki, T.; Nakada, N. Effect of grain size on thermal and mechanical stability of austenite in metastable austenitic stainless steel. Iron Steel Inst. Jpn. 2013, 53, 1224-1230. [CrossRef]

36. Takaki, S.; Fukunaga, K.; Syarif, J. Effect of grain refinement on thermal stability of metastable austenitic steel. Mater. Trans. 2004, 45, 2245-2251. [CrossRef]

37. Challa, V.S.A.; Wan, X.L.; Somani, M.C.; Karjalainen, L.P.; Misra, R.D.K. Strain hardening behavior of phase reversion-induced nanograined/ultrafine-grained (NG/UFG) austenitic stainless steel and relationship with grain size and deformation mechanism. Mater. Sci. Eng. A 2014, 613, 60-70. [CrossRef]

38. Barbier, D.; Gey, N.; Allain, S.; Bozzolo, N.; Humbert, M. Analysis of the tensile behavior of a TWIP steel based on the texture and microstructure evolutions. Mater. Sci. Eng. A 2009, 500, 196-206. [CrossRef]

(C) 2018 by the authors. Licensee MDPI, Basel, Switzerland. This article is an open access article distributed under the terms and conditions of the Creative Commons Attribution (CC BY) license (http://creativecommons.org/licenses/by/4.0/). 